\title{
Biometrics of reversal learning in mice: I. Effects of ITI and strain
}

A. B. CARRAN, State University of New York, College at Brockport, Brockport, N.Y. 14420

Four strains of highly inbred mice, $12 \mathrm{Ss}$ per strain, were run under relevant water deprivation on a T-maze position reversal problem in a factorial design with three levels of ITI. The reversal criterion was six of seven trials correct; each $S$ completed 50 sessions. The ITI had no significant main or interaction effect, there was no significant interaction of strain and environment, and there was little correlation of parents' age with number of offsprings' reversals $(r=-.10)$. Effect of strain was highly significant $(p<.001)$ with "heritabilities" (Fuller \& Thompson, 1960) of .53, 39, and .70 for the 13-, 24-, and 60-sec ITIs, respectively.

In view of the difficulty of establishing equality of environmental components of variance of identical and fraternal twins (Fuller \& Thompson, 1960) and because of similar difficulties associated with the multiple abstract variance design (Cattell, Stice, \& Kristy, 1957), it seems highly desirable to buttress findings in human genetics with a science of comparative psychogenetics which may provide knowledge of phyletic trends in allelic and nonallelic interaction, number of genes, heritability, sex, and maternal effects. The question of which species to choose in establishing a science of comparative psychogenetics is now less problematical in view of recent work on the evolution of neocortex and the role of ecological factors (Diamond \& Hall, 1969). A suitable series might then be mouse, rat, tree shrew, and chimpanzee, preferably with inbred strains as parent generation.

This paper is the first report of a series of experiments on appetitive reversal learning in mice. The research reported here was concerned with the problem of discovering strain differences in mice which indicate that satisfactory scaling can be achieved in later studies. Subsequent work, now in progress, undertakes more sophisticated biometric analysis of the strain differences reported below and will also be concerned with the problem of prenatal maternal effects of hybrid vs inbred dams.

$$
\text { SUBJECTS }
$$

Mice, obtained from Jax Lab, were mated to obtain 12 male offspring of each of the highly inbred strains, ccl29J, ccBalb/cJ, aaC57bl/19J, and bbDBA/IJ. Mates were of the same age, ranging from 83 to 222 days at parturition, and were kept in plastic cages (Scientific Products Model A 4510-1) with wire mesh lids (Model A 45142). The cages were painted black on all sides but the front, filled to a depth of 1 in. with San-I-Cel, and provided for nesting material with nine $3 \times 3$ in. strips torn from paper hand towels. The cages were emptied and cleaned weekly before parturition. Upon sign of pregnancy, the sire was removed. On the day of birth plus 2 (Day 3) the litter was randomly pruned to six and the San-I-Cel only was changed on Day 14 when a handful of chow was placed on the floor of the cage. The pups were weaned on Day 21 and removed to individual Hoeltge Model HB-20 mesh-bottom metal cages where they received ad lib food and water until Day 47. Dams were not mated again until 5 days after weaning. Breeding and aging cages, as well as the testing cubicle, were housed in the same room which was kept at $73 \mathrm{deg} F$ by air conditioning. Lights went on at 4:30 a.m. and off at 9:30 p.m.

\section{APPARATUS}

A 4-ft cubicle, painted flat white and containing two $15-\mathrm{W}$ bulbs on the ceiling, housed the apparatus, a Plexiglas T-maze recessed in a close-fitting enclosure painted flat black, 8 in. high and open at the top for ready insertion of sections of the maze. The maze was designed to eliminate direct handling of S. It consisted of a center section plus three identical and interchangeable end sections with handles fitting grooves in the enclosure so that $S$ could be moved while within an end section, from an arm back to the stem of the enclosure. The center section was separated from the ends by three 21-in.-high guillotine doors, joined at the top to permit simultaneous operation when E pulled or released a cord. The door in the stem was painted with mercury gray enamel so that $S$ could not see $E$ when the door was down. The two clear doors lowered only to within $.25 \mathrm{in}$. of the floor to allow clearance for S's tail. A drinking trough, $1 \times 1 \times .75$ in. deep, was centered at the end of each end section, painted mercury gray on the outside, and contained a .5-in.-high horizontal sheet of Plexiglas with a hole, $.25 \mathrm{in}$. in diam, centered in it to allow insertion of a Plexiglas dipper of $.01-\mathrm{ml}$ capacity. The dipper could be pivoted manually for refilling from a water reservoir under the maze. With reference to inside dimensions, the end sections were 7 in. long and when in place the overall length of the maze from base of stem to top of crossbar was 10 in.; the crossbar was 18 in. long. The interior of the maze was 2 in. wide and $2.25 \mathrm{in}$. high, the sides of .25 -in. and the top of .125-in. Plexiglas. A line painted on the base of the maze, $2.8 \mathrm{in}$. from the end of each end section, defined choice whenever S's nose crossed the line.

A concealed light, in series with a knife switch and two timers, remained off for $8 \mathrm{sec}$ after the switch was closed, went on for the ITI, and then went off to signal the next trial. Bent hooks fastened on the exterior of the maze could be rotated in the direction of S's choice to provide a record. DESIGN AND PROCEDURE

The design was factorial with three levels of ITI $(13,24$, and $60 \mathrm{sec})$ and the four levels of strain. The four Ss of each cell in the design were derived from at least two different dams, and no dam contributed more than five offspring to the total design. No cell of the design was assigned unless all other cells were within two of the same number of assignees. If a litter afforded excess males, Ss were randomly selected at weaning.

On Day 47 or $48, S$ was begun on the $24-h$ water deprivation. This alternated with a day of pretraining, or later, reversal learning, in which water was available afterwards for $24 \mathrm{~h}$. Pretraining consisted of placing $S$ in an end section without handle which was placed in the home cage for $10 \mathrm{~min}$ with $S$ inside and a dipper of water in the trough. At 10-min intervals, the dipper was observed and $S$ removed if the water had been consumed. Six pretraining trials were followed by 50 training sessions with a 51 st session if $S$ reached criterion (at least six of the seven trials of a session correct) on the 50 th trial.

In training, $\mathrm{E}, \mathrm{a} \mathrm{PhD}$ in experimental psychology, first moved $S$ directly from the home cage into an end section, closing it with a plastic insert which was removed as the end section was inserted in the stem of the maze. A stopwatch was started and the doors lifted after $30 \mathrm{sec}$. When the top of S's nose crossed a criterion line, the doors were

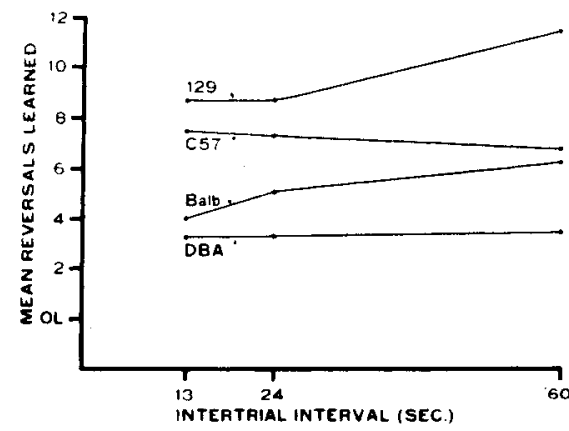

Fig. 1. Mean reversals learned in 50 sessions as a function of ITI and strain. 
lowered and the trial scored. If $S$ had chosen the incorrect alley, the knife switch was thrown so that $8 \mathrm{sec}$ later the concealed light went on, beginning the ITI, and E exchanged the stem and appropriate end section, thereby setting up for the next trial. The same procedure was followed for a correct choice, except that the ITI was not begun until $S$ began drinking or until 3 min had elapsed. Drinking was typically immediate and failed to occur on a total of only two trials. Two mice refused the run on a total of seven sessions and such sessions were terminated after $20 \mathrm{~min}$. These sessions were scored as if a completed noncriterion session. The maze was cleaned of boluses or urine before the next $S$ was run, and at the end of the day it was washed.

\section{RESULTS AND DISCUSSION}

The results are shown in Fig. 1. The ITI parameter had no significant main effect $(F=1.07, \quad \mathrm{df}=2 / 36)$ and $\mathrm{did}$ not significantly interact with strain $(F=.62$, $\mathrm{df}=6 / 36$ ). It was suspected that the absence of a main effect of ITI might be due to compensation for a loss of short-term memory by a gain in overall reverberatory time for long-term memory formation as ITI increased. Therefore, the probabilities of incorrect initial and of incorrect final choices on the session following each criterion session were calculated for each level of ITI, with the prediction that probability of error on the first trial would increase with increasing ITI. It was found that the initial trial probabilities were .62 , .75 , and .68 and the last trial probabilities were $.49, .60$, and .57 for the 13-, 24-, and $60-\mathrm{sec}$ ITIs, respectively. While tending to the direction predicted, the trend of these results is not striking and it seems that ITI makes little difference within the range studied.

The effect of strain was highly significant $(F=16.57, \quad \mathrm{df}=3 / 36, \quad \mathrm{p}<.001)$. Calculating "heritability" after Fuller \& Thompson (1960), but setting $\sigma_{\mathrm{b}}{ }^{2}=\sigma_{\mathrm{g}}{ }^{2}$ and $\sigma_{\mathrm{w}}{ }^{2}=\sigma_{\mathrm{e}}{ }^{2}$ for full genetic correlation, gave heritabilities of $.53, .39$, and .70 respectively, for the 13-, 24-, and 60-sec ITIs. These estimates should of course be regarded as liberal pending subsequent biometric analysis for maternal environmental effect. Little environmental variance was due to maternal age which correlated low with number of reversals of offspring $(\mathrm{r}=-.10, \mathrm{t}=-2.30, \mathrm{df}=46$, $p<.05)$. Data were grouped with respect to strain only and test of homogeneity of variance made. Despite the grouping, no significant interaction of heredity and environment was found $\left(F_{\max }=3.33\right.$, $\mathrm{df}=4 / 11$ ).

Since the count of reversals was made only over 50 sessions, regardless of S's record, data on sessions to criterion as a function of reversal number are quite incomplete except for $129 / \mathrm{J}$ mice, all of which completed the sixth reversal. Nonetheless, it was quite clear that sessions required for the first reversal did not show the increase over sessions for original learning found quite typically in the case of the rat. Except for the Balb strain, which showed little variation as a function of reversal number, it appeared that most of any learning to learn occurred during original learning. Mean sessions to criterion of the $129 / \mathrm{J}$ mice was representative of this trend and, beginning with original learning, was $7.0,5.3,4.2,4.7,5.7,4.3$, and 4.8 . In further distinction from the rat, reversal learning in one session was quite infrequent, occurring only 11 times.

\section{REFERENCES}

CATTELL, R. B., STICE, G. F., \& KR ISTY, N.F. $A$ first approximation to nature-nurture ratios for eleven primary personality factors in objective tests. Journal of Abnormal \& Social Psychology, 1957, 54, 143-159.

DIAMOND, I. T., \& HALL, W. C. Evolution of neocortex. Science, 1969, 164, 251-262.

FULLER, J. L., \& THOMPSON, W. R. Behavior genetics. New York: Wiley, 1960. presence of the line to $0.5 \mathrm{sec}$ while holding it constant in the presence of green did not produce any consistent rate increase or decrease. This change did result, however, in a higher response rate in the presence of the stimulus correlated with the higher reinforcement magnitude.

Relatively few experiments have investigated the effect of different amounts of reinforcement within a session under a multiple schedule in the free-operant setting (Dickson \& Thomas, 1963; Beer \& Trumble, 1965; Shettleworth \& Nevin, 1965). The general finding has been that the rate of responding in the presence of a stimulus correlated with the greater amount of reinforcement is higher than in the presence of the stimulus correlated with the lesser amount. In none of the previous studies has a baseline level of responding been firmly established in which amount of reinforcement was the same and then reduced in the presence of one stimulus and held constant in the presence of the other stimulus. If reducing the reinforcement magnitude reduces the rate of responding in the presence of its correlated stimulus, then an increase in the rate of responding in the constant component (behavioral contrast) should result (Terrace, 1968).

\section{SUBJECTS AND APPARATUS}

Six adult White Cameaux pigeons, maintained at $80 \%$ of their free-feeding weights, served as Ss. The testing chamber was a standard three-key operant-conditioning chamber enclosed in an ice chest. An exhaust fan provided masking for extraneous noise. An Industrial Electronic Engineers multistimulus projector, mounted behind the center key, could illuminate this key with five wavelength stimuli $(501,538,555,576$, and $606 \mathrm{~nm}$ and five orientations of a white line, $7 / 8$ in. high and $1 / 8$ in. wide, on a black background ( $\pm 60 \mathrm{deg}, \pm 30 \mathrm{deg}$, and $0 \mathrm{deg}$ from vertical)

A photocell was mounted in the opening of the magazine. Operation of the magazine lighted the opening and closed the photocell circuit. To eat, the bird had to occlude the photocell which opened the circuit and produced a short electrical pulse. Programming and recording was a c complished with standard electromechanical equipment located in an adjacent room.

\section{PROCEDURE}

After the pecking response was shaped to the center key, pecking this key was reinforced on a variable interval schedule of $30 \mathrm{sec}($ VI 30-sec). The $555 \mathrm{~nm}$ stimulus (S1) and the white vertical line (S2) alternated every $1 \mathrm{~min}$ separated by a 10 -sec blackout. Each animal received 30 1-min cycles daily, 15 of each stimulus. No other illumination reinforced for 20 days with a reinforcement duration of $4 \mathrm{sec}$ in the presence of both a green light and $a$ white vertical line in order to establish a baseline response rate. Reducing the reinforcement duration in the RILLING, Michigan State University, East Lansing, Mich. 48823

Psychon. Sci., 1969, Vol. 16 (5) 